\title{
Assessment of a Planned Municipal Solid Waste Management System in Sri Lanka
}

\author{
DISNA EHELIYAGODA ${ }^{1} *$ NIMAL PREMATILAKE ${ }^{2}$

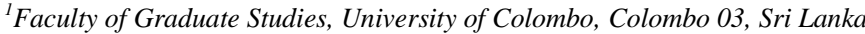 \\ ${ }^{2}$ Balangoda Urban Council, Balangoda, Sri Lanka \\ Correspondence should be addressed to Disna Eheliyagoda; disna.eheliyagoda@yahoo.com
}

\begin{abstract}
Systematic Municipal Solid Waste Management (MSWM) authorities of Sri Lanka contributes to exchange some productive outputs with localities; however it is still not in a successful mode due to limitations and environmental failures in their operation. Most of these local administrations are directly dumping Municipal Solid Waste (MSW) to an open dumping site, this manner of inappropriate disposal of MSW is become a major threat to the environment and public health in developing countries like Sri Lanka. This study was conducted for the MSWM practices of Balangoda Urban Council. The research was performed based on analyzing information obtained from field observations; reports; literature; questionnaire distribution among community; and a series of formal interviews with major stakeholders. The ongoing MSWM practices of Balangoda Urban Council encompass six categories as waste minimization and handling; waste collection; on-site separation; waste transportation; further management including grading, composting, recycling, producing sludge fertilizer; and final disposal to an open dump site. Apart from those, training sessions on MSWM are also being conducted. The purpose of this paper is to assess current status of urban waste management scenario and highlight strengths and weaknesses to understand the sustainability of the system which would help any local authority to improve MSWM. (C) JASEM
\end{abstract}

http://dx.doi.org/10.4314/jasem.v20i1.7

KEYWORDS: Municipal Solid Waste Management, Municipal Solid Waste, Open Dumping, Urban Council, Balangoda

Introduction

Municipal solid waste management (MSWM) is an important issue in today's world as it deals with budget allocations of local municipality, public acceptance and adverse impacts on environment (Ramakrishna, 2013). Generally in developing countries, a waste management system encompasses planning, engineering, organization, administration, financial and legal aspects of activities associated with generation, growth, storage, collection, transport, processing and disposal in an environmentally compatible manner adopting principles of economy and aesthetics (Dasgupta, 2013). It has been a local government responsibility to provide the service of urban solid waste management. The governments spend about $20-$ $50 \%$ of their budget in solid waste management, however only $20-80 \%$ of the waste is managed (Simon, 2008). Therefore, management procedures of municipal waste in many developing countries are rather chaotic and need to be analyzed and strengthen further (Bandara, 2008).

In Sri Lanka, municipal councils, urban councils and divisional councils are responsible for MSWM in their corresponding areas. In most cases, municipal councils and urban councils use planed and systematic waste management practices in daily basis. They normally utilize many interrelated functional elements associated with prevention; minimization; generation, characteristics and composition; on-site storage, handling and separation; collection; transfer and transport; sorting; reuse; recycling; composting; incineration and energy recovery; treatment and final disposal. However, the planned waste management authorities of Sri Lanka also face problems due to inadequacies in their MSWM procedure. Therefore, this research aims to understand the status quo of planned urban waste management practices in Sri Lanka taking Balangoda Urban Council as a case.

Balangoda Urban Council which is the local authority responsible for overall urban waste management system in Balangoda suburb. Balangoda is situated in Ratnapura district of Sri Lanka. It is located between $80^{\circ} 35^{\prime}$ to $80^{\circ} 55^{\prime}$ East longitudes and $60^{\circ} 30^{\prime}$ to $60^{\circ}$ $45^{\prime}$ North latitudes. The Balangoda Urban Council area comprises a total land area of $16.2 \mathrm{~km}^{2}$. The mean temperature of Balangoda is $27^{\circ} \mathrm{C}$. As a consequence of geographical settings, the annual rainfall averages from $1,500 \mathrm{~mm}$ to $1,600 \mathrm{~mm}$ which sometimes exceeds $2,000 \mathrm{~mm}$. The total population of Balangoda area is approximately 23,220. With regard to the commuting population, Balangoda Urban Council facilitates around 40,000 people who enter the town for various purposes daily (BUC Report, 2013). 


\section{MATERIALS AND METHODS}

Both primary and secondary data to assess the current status of MSWM in Balangoda urban area was collected using different methods such as field observations, taking photography, reviewing governmental reports and related literature, questionnaire distribution among 500 citizens of the area and six focused interviews with major stakeholders concerned. The survey data was collected from October, 2013 to April, 2014.

\section{RESULTS AND DISCUSSION}

Generation, Sources and Composition of Municipal Solid Waste: Balangoda Urban Council is the responsible authority for overall waste management within Balangoda town area which includes only Municipal Waste. The current MSW generation on daily basis in Balangoda town is 20 tonnes which is augmented up to 25 tonnes in Sundays because it is the usual fair day for citizens. In addition, the solid waste quantity in the festival season (Sinhala-Tamil New Year period) increases from 5-6 tonnes/day compared with typical value which runs on only 5-6 days (in April) within the entire year. The main sources of MSW in Balangoda Urban Council division are households, commercial establishments such as markets and restaurants, municipal services (street sweeping and drain cleaning) as well as institutions including schools and government offices. In addition to those, construction and demolition wastes are also taken into account of management in a very small quantity.

Municipal Waste of Balangoda town typically consists of a very high percentage of perishable organic food materials with moderate amounts of 11 category recyclable and other useful materials as paper, cardboard, polythene, plastic, glass bottles, coconut shells, steel, king coconut shells, tins, tires and tubes as well as low contents of discarding materials like batteries, lunch sheets, regiform, compact disks, laminating papers, hair, broken bulbs, industrial glass, building materials, aluminum and tree branches which are finally released to the open dumping site. The moisture content in MSW is also high on a wet weight basis. The current MSWM practices of Balangoda Urban Council encompass six segments as given below.

Waste Minimization and Prevention: For a proper Municipal Waste minimization and prevention, Balangoda Urban Council has delivered 100 bins for preparation of compost among residents. The purpose of such activity is to reduce the waste generation through composting process and use this fertilizer for home gardening. However, the task is still a somewhat failure due to lack of staff members for a successful monitoring. As a result of well managed awareness programmes, Balangoda Urban Council has meaningfully decreased the levels of vegetable waste generation at present. Furthermore, this local authority has already implemented several other management practices such as instituting a waste tax, maintaining a waste purchasing centre, conducting school and rural based waste management programmes for minimization and prevention of waste generation within the area.

Waste Collection: Balangoda Urban Council handles garbage collection using a time-table and a map. They are mainly responsible to collect organic food waste daily. The waste collection is conducted according to two shift-works as morning shift from 5.00 a.m. to 2.00 p.m. and night shift from 2.00 p.m. to 10.00 p.m. Urban Council members have deployed two labourers for sweeping roads at least 30 minutes before the garbage collection vehicles arrive in both day and night shifts separately. This local authority has also distributed barrels to each and every meat and fish stall to put waste. Urban Council owned tractors and land masters are used to collect rubbish. Furthermore, lorry dustbins are also used for safe collection of waste. Only two labourers per one vehicle engage to collect street trash daily. Garbage should be collected in each street once a day and twice a day in each main street. For a systematic collection of waste, they have introduced "Bell Collection System" (Music Playing System) to residents. For the collection of recyclable and other useful waste as well as discarding materials, a separate tractor is used twice a week.

On-site Separation and Handling: Especially on-site separation is done for dividing waste as perishable and non-perishable materials. For this task, two bins have been introduced to citizens to put waste separately and they are placed in necessary sides of the road. When collecting waste, polythene is collected separately and all types of polythene are collected together. Moreover, e-waste materials such as computers, mobile phones as well as regiform products are also collected separately.

Waste Transportation: Collected waste is transported to the Urban Council owned solid waste management centre located at Bankiyawaththa, Balangoda. Furthermore, garbage is unloaded into the compost yard at that centre once in each 45 minutes usually.

Further Management: The solid waste management centre is the most important part within the garbage management process of Balangoda Urban Council. The centre follows four methods to further management of existing waste as grading, composting, recycling and producing sludge 
fertilizer. Moreover, this centre also contributes to distribute practical knowledge on MSWM.

Grading: Grading of garbage is totally done manually by using labourers daily; however it is still not more successful. Moreover, an amount of 4 tonnes of waste is graded by 4 labourers within 45 minutes. When grading, non-perishable materials are separated into the 11 items whereas food waste is sorted further to remove unnecessary things. The amount of king coconut shells collected daily are cut into pieces and dried well. Those dried shells are used as a fuel. The daily collected paper and cardboard are further graded into three categories as cardboard, books and papers. Usually, the Urban Council sells them for recycling purposes. Plastic is graded into two types as pet bottles and other plastics. Pet bottles are sold at a booked price and the other plastics are sold at a common price. Furthermore, the glass bottles are separated as white bottles and brown bottles. These collected bottles are sold to local buyers at a same price. On the other hand, collected chips and circuits within e-waste are also sold to local buyers.

Composting: Balangoda Urban Council uses Open Windrow method for overall composting process. However, the quality of production has decreased due to high moisture content of compost, improper height and width of compost piles (existing height $-12 \mathrm{ft}$ and width $-5 \mathrm{ft}$ ) compared with the recommended level (5-10 ft height and $10-20 \mathrm{ft}$ width) and weak performance in turning piles. As a consequence of poor management within the composting process, some environmental issues have already aggregated such as spreading bad smell and leachate problems.

Recycling: This is mainly done as raw material preparation according to the demand of buyers using a crushing machine for the plastic parts of e-waste and polythene. According to the overall procedure, separated plastic and polythene is fragmented into small pieces after their hand washing. Next, these pieces are subjected to the recycling process. All recycled polythene is sold at a reasonable price to a local buyer who lives near the town. Recycled plastics are also sold at a common price.

Producing Sludge Fertilizer: Recently, Balangoda Urban Council has begun to collect 'night soil' of the Urban Council area and this contaminated water based liquid is subjected to manufacture a fertilizer. This fertilizer is used to enhance the productivity of agricultural fields. The released water from the process is treated using a wastewater treatment system. Furthermore, this treated water is used for washing purposes of labourers in the solid waste management centre.

Training and Education: A course called "Solid Waste Management Assistant" is currently continued by the Balangoda Urban Council at the solid waste management centre for training necessary workers in the waste management field according to the country's requirement. A certificate of National Vocational Qualifications (NVQ) Level 4 will be awarded for those who complete the course successfully.

Final Disposal: Balangoda Urban Council maintains a small open dump site close to the solid waste management centre to discard about $10 \%$ of waste which cannot be managed using current waste management methods. Although, it was introduced as a controlled landfill, short term and long term environmental problems have already aggregated due to improper dumping, some poor management practices and situation in a slope. However, the attention to cure these issues is in a minimum level at the moment.

Acknowledgement: This study was financially supported by Balangoda Urban Council of Sri Lanka.

\section{REFERENCES}

Balangoda Urban Council (2013). Report of Waste Management Project. Balangoda, Sri Lanka.

Bandara, N. J. G. J. (2008). Municipal Solid Waste Management - The Sri Lankan Case. Proceedings of the Conference on Developments in Forestry and Environment Management in Sri Lanka, Colombo, Sri Lanka.

Dasgupta, T. (2013). Sustainable Municipal Solid Waste Management of Bhopal City. International Journal of Scientific Engineering and Technology, 2(11): 1103-1106.

Ramakrishna, V. (2013). Life Cycle Assessment Model for Integrated Solid Waste Management. International Journal of Engineering Research \& Technology, 2(9): 1742-1748.

Simon, A. M. (2008). Analysis of Activities of Community Based Organizations Involved in Solid Waste Management, Investigating Modernized Mixtures Approach: The case of Kinondoni Municipality, Dar es Salaam, Tanzania. MSc Dissertation, Wageningen University and Research Centre, Wageningen, Netherlands. 


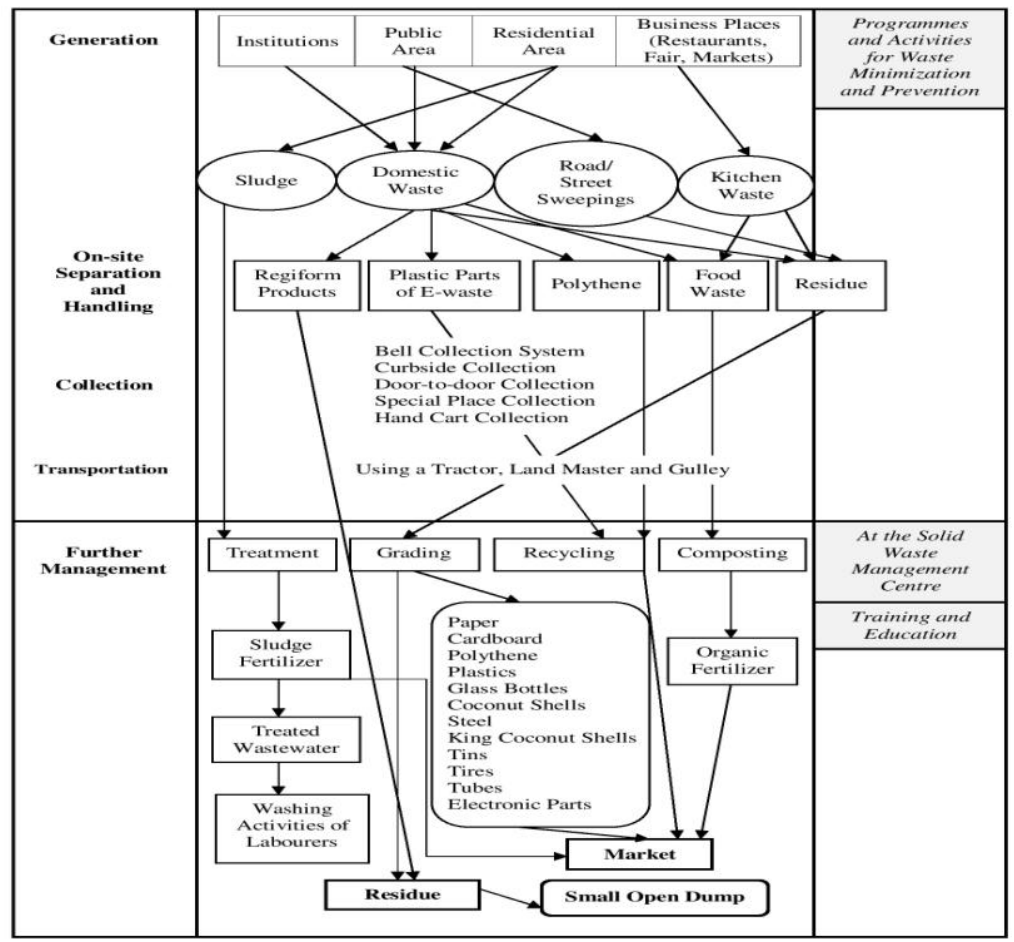

Fig 1: Summary of MSWM System to Balangoba Urban Council 